Article

\title{
Enhancement of the Efficiency of Bioethanol Production by Saccharomyces cerevisiae via Gradually Batch-Wise and Fed-Batch Increasing the Glucose Concentration
}

\author{
Yi-Huang Chang ${ }^{1}$, Ku-Shang Chang ${ }^{1}$, Chien-Yu Chen ${ }^{2}$, Chuan-Liang Hsu ${ }^{3}$, \\ Tsan-Chang Chang ${ }^{4}$ and Hung-Der Jang ${ }^{1, *}$ \\ 1 Department of Food Science, Yuanpei University of Medical Technology, Hsinchu 300, Taiwan; \\ yihuang@mail.ypu.edu.tw (Y.-H.C.); kushang@mail.ypu.edu.tw (K.-S.C.) \\ 2 Institute of Food Science, Yuanpei University of Medical Technology, Hsinchu 300, Taiwan; \\ fan598830@yahoo.com.tw \\ 3 Department of Food Science, Tunghai University, Taichung 407, Taiwan; clh@thu.edu.tw \\ 4 Department of Nursing, Mackay Junior College of Medicine, Nursing, and Management, \\ Taipei 11260, Taiwan; s354@mail.mkc.edu.tw \\ * Correspondence: hungder@mail.ypu.edu.tw; Tel.: +886-3-538-1183 (ext. 8482); Fax: +886-3-610-2342
}

Received: 24 May 2018; Accepted: 11 June 2018; Published: 13 June 2018

\begin{abstract}
High initial glucose concentrations may inhibit glucose utilization and decrease ethanol fermentation efficiency. To minimize substrate inhibition, the effects of feeding yeast with different glucose concentrations on the ethanol production by batch and fed-batch cultures in a 5-L fermentor were investigated. When a batch culture system with Saccharomyces cerevisiae was used for ethanol fermentation with glucose concentrations ranging $10-260 \mathrm{~g} / \mathrm{L}$, as a result, $0.2-7.0 \mathrm{~g} / \mathrm{L}$ biomass and 5.1-115.0 g/L ethanol were obtained. However, substrate inhibition was observed with the initial glucose concentrations greater than $200 \mathrm{~g} / \mathrm{L}$ in the fermentative media. When a fed-batch culture system (an initial glucose concentration of $180 \mathrm{~g} / \mathrm{L}$ and total glucose concentration of $260 \mathrm{~g} / \mathrm{L}$ ) was performed, the maximum ethanol concentrations and ethanol yield were significantly higher than those of the batch cultures. The cell biomass, maximum ethanol concentration, and ethanol yields for the fed-batch fermentation cultures were $8.3 \mathrm{~g} / \mathrm{L}, 130.1 \mathrm{~g} / \mathrm{L}$ and $51 \%(100 \%$ of the theoretical value), respectively. The results indicated that high ethanol concentration and ethanol yield could be achieved by the fed-batch cultures with total glucose concentrations up to $260 \mathrm{~g} / \mathrm{L}$.
\end{abstract}

Keywords: bioethanol; glucose inhibition; batch culture; fed-batch culture; fermentor

\section{Introduction}

The increasing consumption of crude oil and greenhouse effects connected with petroleum combustion has initiated a worldwide concern for the development of alternative and renewable fuels that are environmentally friendly. Bioethanol is believed to be one such alternative, which can be produced from renewable biomasses such as sugar, starch and cellulosic materials. Bioethanol is also a renewable energy source that is well positioned to be an excellent clean-burning, high-energy alternative fuel to gasoline. Nowadays, bioethanol is commonly blended with conventional gasoline for use in automobile fuels to reduce greenhouse gases emissions. Because the raw materials used to produce bioethanol come from renewable resources with low $\mathrm{CO}_{2}$ emissions, bioethanol has offered many distinctive advantages over fossil fuels [1].

Saccharomyces cerevisiae is the well-known brewing yeast that can ferment glucose into ethanol under anaerobic conditions. The microorganism is ideal for ethanol production because it possesses 
several properties, including: fast growth rates, efficient glucose utilization and ethanol production, and a tolerance for environmental stresses such as high ethanol concentration [2], wide range of $\mathrm{pH}$ [3] and low oxygen levels [4]. Similar to in most organisms, the metabolic pathway of glycolysis converts glucose into pyruvate, which can then be fermented into ethanol under anaerobic conditions. The energy for growth of $S$. cerevisiae cells during ethanol fermentation is mostly provided by the glycolytic pathways. Further, ethanol production by S. cerevisiae is economically efficient and industrially feasible because $S$. cerevisiae reproduces quickly and thus meets the requirements of the large pilot-scale processes [5]. The growth of a microorganism is strongly influenced by medium composition, and the production of ethanol is cell-dependent. The rapid growth of S. cerevisiae in batch cultures with limited nutrients results in the production of ethanol; however, high initial glucose concentration in the fermentative media may cause substrate inhibition, which substantially lowers the fermentation efficiency. Thus, for an effective fermentation process, the major concern is the optimization of the composition of cultural media and parameters. To meet industry demand, it is also necessary to improve the performance of the system and increase the ethanol yield without increasing the cost of production $[6,7]$. Besides, if ethanol fermentation is to be of practical use in the industry, the ethanol yield can constitute as much as $93 \%$ of its theoretical value of the ratio of ethanol produced to sugar consumed [8].

High initial glucose concentrations in the culture media may cause substrate inhibition and thus lead to a decrease in ethanol production. Many studies on ethanol fermentation technology described that declines in growth and viability of yeasts occurred when sugar concentrations in the media increase from 120 to $180 \mathrm{~g} / \mathrm{L}$ [9-13], likely because of yeast osmotic stress [11,14]. The effect of osmotic stress on cell metabolism had also been studied by Thomas and coworkers [15], and they deduced that the syntheses of glycolytic enzymes, and the enzymes of the hexose monophosphate pathway, were regulated by sugar concentration. However, Mauricio and Salmon [16], and Salmon and colleagues [17] proved that the principal factor limiting fermentative metabolism was an inhibition of sugar transport. Sugar transport mechanism in yeasts has been characterized by the presence of several transporters that have a specific affinity to glucose. Those transporters presenting high affinity to the substrate that cause catabolic repression; however, they are not detected in fermentation at high sugar concentrations [18,19].

Considering an efficient and economical ethanol production, rapid fermentation is required to produce high ethanol concentrations; therefore, a yeast strain must have a good specific growth rate and specific ethanol production rate at high osmotic stress and ethanol concentrations. Many parameters during batch fermentation will cause a decrease in the specific rate of yeast growth, and inhibition can be caused by either the substrate or the end-product. Other fermentation modes have been attempted to overcome product and substrate inhibition and to improve the ethanol tolerance of yeasts. Among them, the choice of an appropriate process mode and process optimization, such as fed-batch, continuous or semi-continuous [20], and/or manipulation of the composition of cultural media [21], has been one of the most widely explored strategies. The fed-batch culture with the intermittent feeding of glucose and without removal of the fermentation broth, is one of the most common strategies used to produce ethanol in the industry. The advantages of this process mode include the reduction of substrate and end-product inhibition, higher dissolved oxygen rate, higher saccharification rate, decreased fermentation time, and higher productivity of ethanol [22,23]. There have been some studies on the effect of initial glucose concentration as well as fed-batch mode of ethanol fermentation on step-feeding reactor [12,23]; however, we demonstrate a competitive and efficient process as a result of the concomitant increase in cell growth rate and biomass yield, and achieved comparatively higher ethanol performance. The ethanol fermentation processes by batch and fed-batch cultures of S. cerevisiae BCRC 21812 using corncob hydrolysate had been compared in our previous report [24]. The results also showed that the fed-batch fermentation had showed a higher ethanol yield than that of the batch fermentation. 
The main objective of this work was to develop an economical bioprocess to produce ethanol using an ethanol-tolerant strain of the yeast S. cerevisiae, through large-scale laboratory experiments. Fermentative assays were performed to evaluate the effects of initial glucose concentration, residual glucose concentration, yeast biomass on ethanol yield and ethanol conversion rate. The fermentation processes with low (1-10\%) and high (15-26\%) initial glucose concentrations in the batch and fed-batch cultures of S. cerevisiae BCRC 21812 were also compared. High ethanol concentrations and ethanol yields were achieved by the fed-batch mode of culture at the total glucose levels as high as $26 \%$. The growth kinetics of the S. cerevisiae during the ethanol fermentation were compared at different glucose concentrations to determine whether it would be feasible for the industry to run fermentation processes at higher sugar concentrations.

\section{Materials and Methods}

\subsection{Microorganisms and Cultivation}

The yeast strain, S. cerevisiae BCRC 21812, was purchased from the Bioresources Collection \& Research Center (Hsinchu City, Taiwan) and used as the inoculum for ethanol fermentation. Yeast cultures were maintained in a DPY medium containing $2 \%(w / v)$ dextrose, $1 \%(w / v)$ peptone and $0.5 \%(w / v)$ yeast extract at $25^{\circ} \mathrm{C}$ for $48 \mathrm{~h}$. The initial $\mathrm{pH}$ of cultural media was adjusted to 6.5 prior to sterilization at $121^{\circ} \mathrm{C}$ for $20 \mathrm{~min}$.

\subsection{Media and Fermentations}

Yeast for inoculation was grown in Erlenmeyer flasks filled with YMB medium containing (g/L): glucose, 10; peptone, 5; yeast extract, 3; malt extract, 3 . After being incubated at $25{ }^{\circ} \mathrm{C}$ and being shaken at $140 \mathrm{rpm}$ for $14 \mathrm{~h}$, the yeast cells were inoculated at about $1.0 \times 10^{7}$ cells $/ \mathrm{mL}$ into the culture medium to initiate the fermentation. The ethanol fermentation was performed in a 5-L stirred fermentor (BTF-5, Biotop Process \& Equipment Inc., Taichung, Taiwan) with a 3-L working volume. The batch fermentations were carried out in a medium consisting of $1-26 \%(w / v)$ glucose, $0.5 \%(w / v)$ peptone and $0.25 \%(w / v)$ yeast extract at an initial $\mathrm{pH}$ 6.0. The medium for fed-batch fermentation was $18 \%(w / v)$ glucose, $0.5 \%(w / v)$ peptone and $0.25 \%(w / v)$ yeast extract. After $24 \mathrm{~h}$ and $48 \mathrm{~h}, 4 \%$ glucose solution was added. Agitation and vortex formation was provided with six-bladed impellers and four side-walled baffle plates. The cultures were agitated at the rates of $600 \mathrm{rpm}$ for $24 \mathrm{~h}$, after which the agitation speed was reduced to $100 \mathrm{rpm}$. The corresponding aeration rate was initially set at $3.0 \mathrm{vvm}$ for aerobic growth of the yeast and adjusted to $0.5 \mathrm{vvm}$ after $24 \mathrm{~h}$ of aeration to create a more anaerobic environment for inducing ethanol production. Dissolved oxygen was measured polarographically by an oxygen electrode. Antifoaming agent was added when required. Samples were drawn at regular intervals from the fermentative broth and analyzed for biomass, $\mathrm{pH}$, glucose and ethanol concentrations. Samples were collected regularly, and levels of glucose and ethanol were analyzed by HPLC.

\subsection{Analytical Methods}

Samples were withdrawn from the fermentation broth, and yeast biomass was determined by measuring cell optical density, recorded with a Ultrospec 2100 pro-spectrophotometer set at $600 \mathrm{~nm}$ (GE Healthcare Co., Barrington, IL, USA). Wet cells were collected by centrifugation at $5000 \times g$ and were washed with the same volume of distilled water. Dry cell weight was obtained by drying wet cells from a $100 \mathrm{~mL}$ culture broth at $100^{\circ} \mathrm{C}$ overnight. The reducing sugars liberated by these reactions were measured using the 3,5-dinitrosalicylic acid method of Miller [25], with glucose as the standard.

The concentrations of glucose and ethanol were determined by cation exchange HPLC (Waters Co., Milford, MA, USA) with a $300 \mathrm{~mm} \times 6.5 \mathrm{~mm}$ Sugarpak column. Meanwhile, the mobile phase consists of secondary de-ionized water with a flow rate of $0.5 \mathrm{~mL} / \mathrm{min}$. All samples, with injection volume set at $20 \mu \mathrm{L}$, were filtered through a $0.22 \mu \mathrm{m}$ filter and then injected into the HPLC column with the column temperature maintained at $90^{\circ} \mathrm{C}$. The HPLC eluate was detected by a refractive index detector 
at $50{ }^{\circ} \mathrm{C}$. The ethanol yield (\%) was defined as the ratio of the concentration of ethanol produced and glucose consumed.

\subsection{Statistical Analysis}

The triplicate data were subjected to an analysis of variance for a completely random design using Statistical Analysis System program (SAS Institute Inc., Cary, NC, USA). Comparison of means was analyzed by Duncan's multiple range test and differences were considered significant of $p<0.05$.

\section{Results}

\subsection{Ethanol Production of the Batch Culture with 4-10\% Glucose}

To study the effect of glucose concentration on ethanol production, batch fermentation for ethanol production was performed in the media containing various concentrations of glucose as the main carbon source. The time courses of glucose and ethanol concentrations in batch fermentation with initial $4 \%(w / v)$ glucose are shown (Figure 1). Glucose was depleted within $20 \mathrm{~h}$, by which time the ethanol concentration and ethanol yield reached $1.6 \mathrm{~g} / \mathrm{L}$ and $50 \%$, respectively. The average glucose consumption rate was $1.99 \mathrm{~g} / \mathrm{L} / \mathrm{h}$ for $20 \mathrm{~h}$ of cultivation. The glucose concentration decreased coincidentally with the increase in cell biomass and ethanol concentration. The yeast cell biomass increased to a maximum of $1.7 \mathrm{~g} / \mathrm{L}$ and the $\mathrm{pH}$ decreased rapidly from 5.5 to 3.5 in the first $18 \mathrm{~h}$ of fermentation. The decrease in dissolved oxygen from an initial of $100 \%$ to less than $1 \%$ after $18 \mathrm{~h}$ of incubation created an anaerobic environment, permitting a rapid increase in the production of ethanol. Similar changes were observed for residual glucose, $\mathrm{pH}$, dissolved oxygen content and biomass when the cultures were started with $10 \%$ glucose $(w / v)$ (Figure 2). For the initial $12 \mathrm{~h}$ of cultivation, the average glucose consumption rate was $1.25 \mathrm{~g} / \mathrm{L} / \mathrm{h}$ when the initial glucose concentration was $10 \%$. During the next $18 \mathrm{~h}$ (the period from 12 to $30 \mathrm{~h}$ ), glucose consumption increased at an average rate of $3.06 \mathrm{~g} / \mathrm{L} / \mathrm{h}$ and the total sugar consumption rate was $2.51 \mathrm{~g} / \mathrm{L} / \mathrm{h}$. The results showed that the glucose consumption rate in the $10 \%(w / v)$ glucose culture was slowed down and exhausted by $30 \mathrm{~h}$ of fermentation. The maximal cell biomass $(5.1 \mathrm{~g} / \mathrm{L})$, ethanol concentration $(48.7 \mathrm{~g} / \mathrm{L})$ and ethanol yield $(50.8 \%)$ were achieved by $30 \mathrm{~h}$ of fermentation. The maximum values of volumetric cell mass production rate $(0.17 \mathrm{~g} / \mathrm{L} / \mathrm{h})$, specific growth rate $(0.18 / \mathrm{h})$ and ethanol production rate $(1.62 \mathrm{~g} / \mathrm{L} / \mathrm{h})$ were found in the cultures with glucose concentration at $10 \%(w / v)$ (Table 1$)$.

Table 1. Kinetic parameters for the batch and fed-batch ethanol fermentation.

\begin{tabular}{cccccc}
\hline Fermentation Type & $\begin{array}{c}\text { Glucose } \\
\text { Concentration } \\
(\mathbf{g} / \mathbf{L})\end{array}$ & $\begin{array}{c}\text { Glucose } \\
\text { Consumption } \\
\text { Rate }(\mathrm{g} / \mathrm{L} / \mathbf{h})\end{array}$ & $\begin{array}{c}\text { Volumetric Cell } \\
\text { Mass Production } \\
\text { Rate }(\mathrm{g} / \mathrm{L} / \mathbf{h})\end{array}$ & $\begin{array}{c}\text { Specific } \\
\text { Growth } \\
\text { Rate }(/ \mathbf{h})\end{array}$ & $\begin{array}{c}\text { Ethanol } \\
\text { Production } \\
\text { Rate }(\mathrm{g} / \mathrm{L} / \mathbf{h})\end{array}$ \\
\hline & 10 & 0.71 & 0.04 & 0.01 & 1.02 \\
Batch fermentation & 40 & 1.99 & 0.09 & 0.05 & 1.12 \\
& 100 & 3.06 & 0.17 & 0.18 & 1.62 \\
& 150 & 3.13 & 0.12 & 0.14 & 1.61 \\
\hline Fed-batch fermentation & 180 & 2.5 & 0.10 & 0.09 & 1.25 \\
& 200 & 2.08 & 0.07 & 0.07 & 1.08 \\
\hline
\end{tabular}




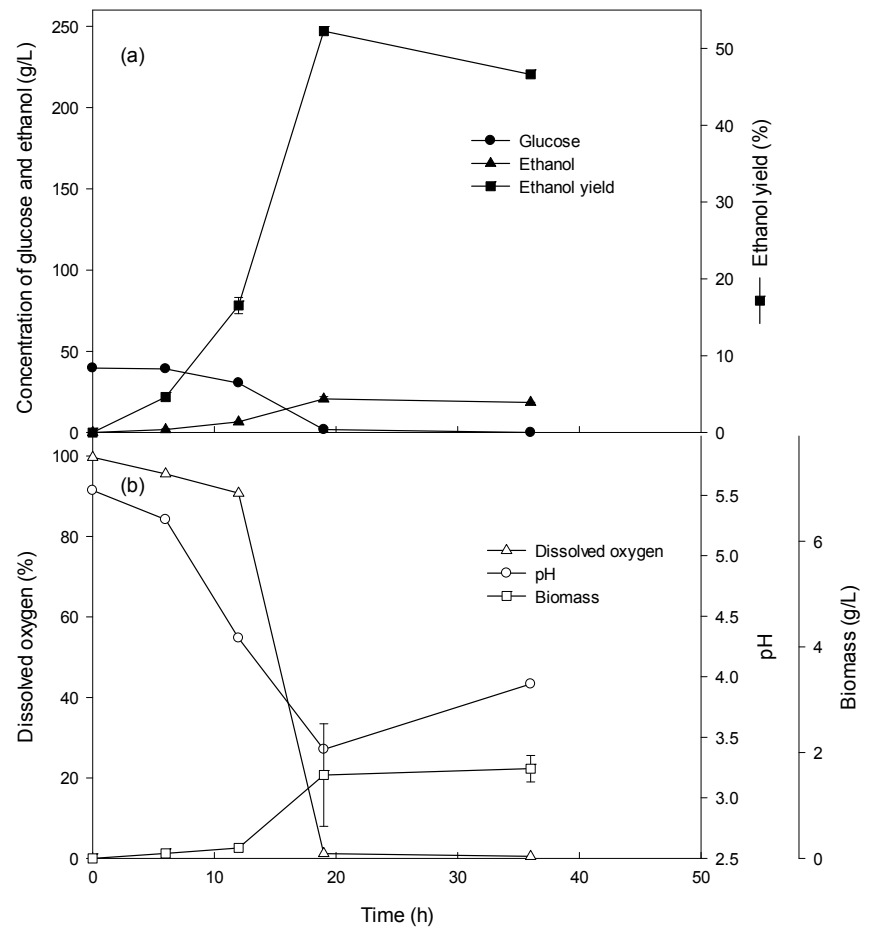

Figure 1. Time course of (a) glucose, ethanol concentration, and ethanol yield change, (b) dissolved oxygen, $\mathrm{pH}$, and biomass in the batch cultures of S. cerevisiae BCRC 21812. The initial glucose concentration was $4 \%(w / v)$.

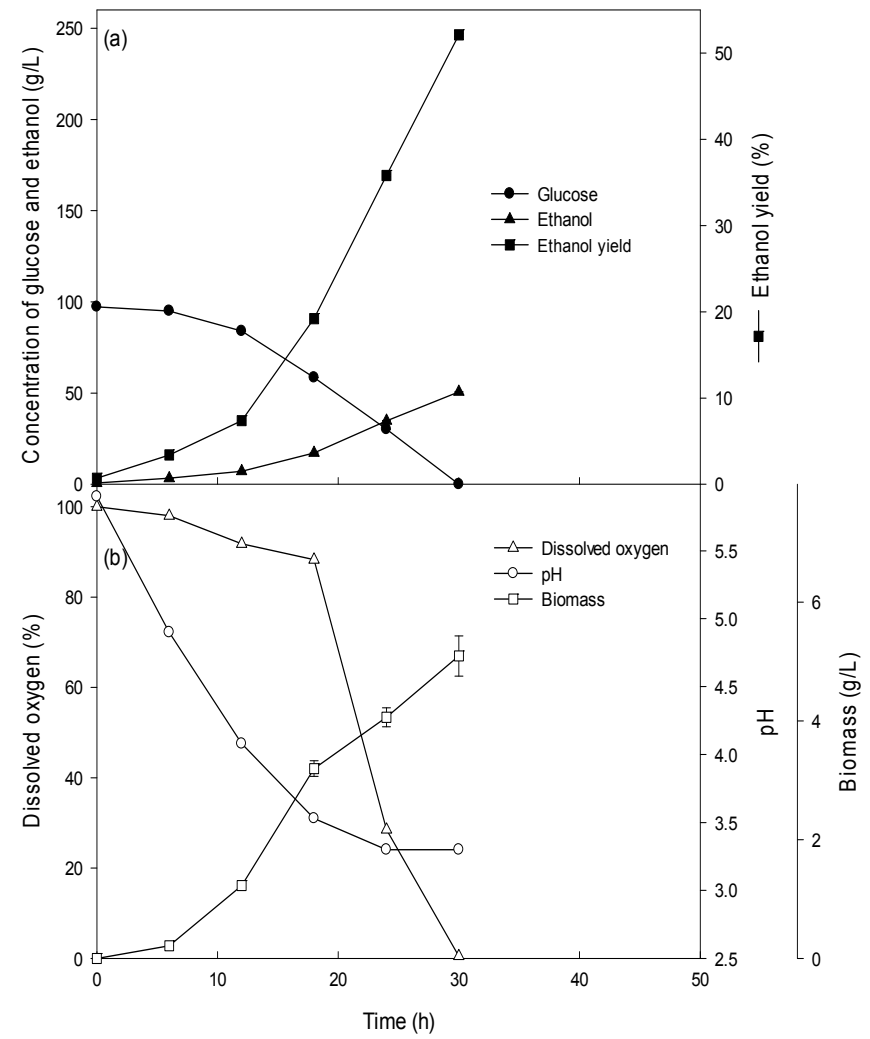

Figure 2. Time course of (a) glucose, ethanol concentration, and ethanol yield change, (b) dissolved oxygen, $\mathrm{pH}$, and biomass in the batch cultures of S. cerevisiae BCRC 21812. The initial glucose concentration was $10 \%(w / v)$. 


\subsection{Ethanol Production of the Batch Culture with High Concentrations (15-26\%) of Glucose}

When an initial glucose concentration was elevated to $15 \%(w / v)$, the average glucose consumption rate increased from $2.29 \mathrm{~g} / \mathrm{L} / \mathrm{h}$ to $3.75 \mathrm{~g} / \mathrm{L} / \mathrm{h}$ for the first and next $24 \mathrm{~h}$, respectively. The total sugar consumption rate was $3.13 \mathrm{~g} / \mathrm{L} / \mathrm{h}$ for $48 \mathrm{~h}$ of incubation. Glucose consumption rate in the culture initiated with $15 \%(w / v)$ glucose was slowed down and exhausted by $48 \mathrm{~h}$ of fermentation (Figure 3). Concentrations of ethanol increased rapidly during the first $48 \mathrm{~h}$ of fermentation. The ethanol concentration $(77.5 \mathrm{~g} / \mathrm{L})$ and ethanol yield $(51 \%)$ reached the maximum values after $48 \mathrm{~h}$ of incubation. It took a much longer fermentation time $(48 \mathrm{~h})$ to obtain the maximal cell biomass in the $15 \%(w / v)$ glucose cultures, when compared to the culture that was began with $10 \%(w / v)$ glucose $(30 \mathrm{~h})$.

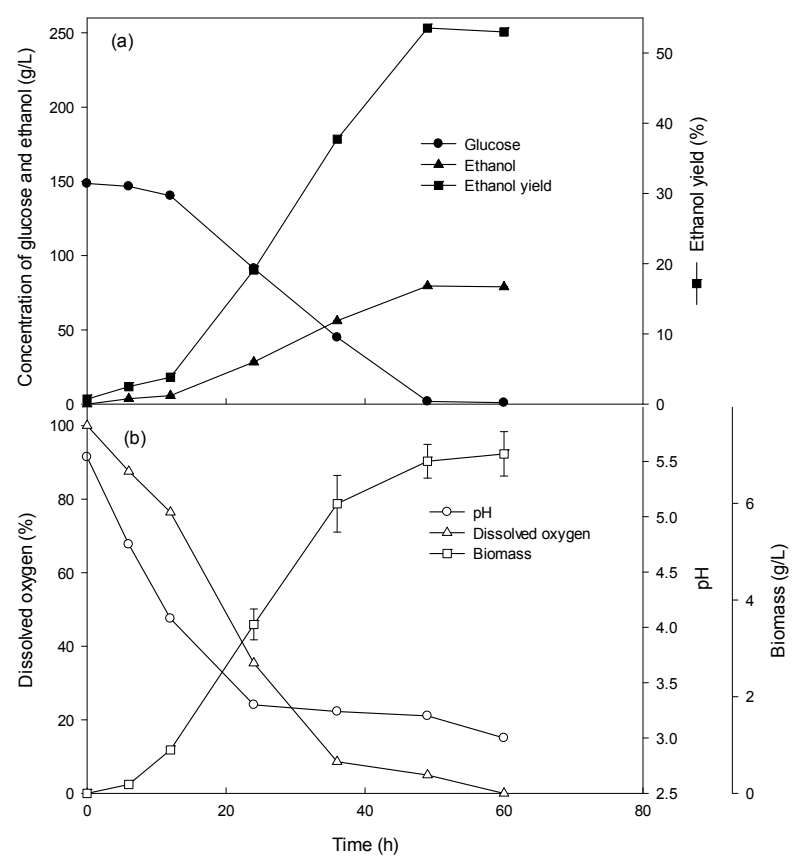

Figure 3. Time course of (a) glucose, ethanol concentration, and ethanol yield change, (b) dissolved oxygen, $\mathrm{pH}$, and biomass in the batch cultures of S. cerevisiae BCRC 21812. The initial glucose concentration was $15 \%(w / v)$.

The time course of the batch fermentation with $18 \%(w / v)$ glucose is shown in Figure 4. The rates of glucose consumption were maintained steadily for $72 \mathrm{~h}$ of incubation and the total sugar consumption rate was calculated to be $2.5 \mathrm{~g} / \mathrm{L} / \mathrm{h}$. It was observed that only minor amounts $(0.2 \mathrm{~g} / \mathrm{L})$ of residual glucose were detected even after $72 \mathrm{~h}$ of fermentation. In addition, the cell biomass of $6.9 \mathrm{~g} / \mathrm{L}$, volumetric cell mass production rate of $0.10 \mathrm{~g} / \mathrm{L} / \mathrm{h}$ and specific growth rate $(\mu)$ of $0.09 / \mathrm{h}$ were found in the cultures with initial glucose concentration at $18 \%$. However, a marked change in the glucose consumption rate was observed in the cultures started with $26 \%(w / v)$ glucose. Glucose depletion was not completely achieved until $120 \mathrm{~h}$ (Figure 5). For the initial $72 \mathrm{~h}$ of cultivation, the average glucose consumption rate was $2.36 \mathrm{~g} / \mathrm{L} / \mathrm{h}$. During the next $48 \mathrm{~h}$ (the period from 72 to $120 \mathrm{~h}$ ), glucose consumption decreased at an average rate of $1.67 \mathrm{~g} / \mathrm{L} / \mathrm{h}$. Therefore, the total sugar consumption rate was $2.09 \mathrm{~g} / \mathrm{L} / \mathrm{h}$. In addition, the maximal cell biomass, volumetric cell mass production rate and specific growth rate $(\mu)$ were significantly decreased to $5.6 \mathrm{~g} / \mathrm{L}$, of $0.05 \mathrm{~g} / \mathrm{L} / \mathrm{h}$ and of $0.04 / \mathrm{h}$, respectively. Furthermore, the ethanol yield decreased sharply to $44.7 \%$ in the culture with $26 \%(w / v)$ glucose. As shown in Table 1, significant decrease in the rates of the glucose consumption, specific microbial growth, and ethanol production rate were observed at the very high glucose concentration $(26 \%, w / v)$ when compared with the cultures with $18 \%(w / v)$ glucose. 


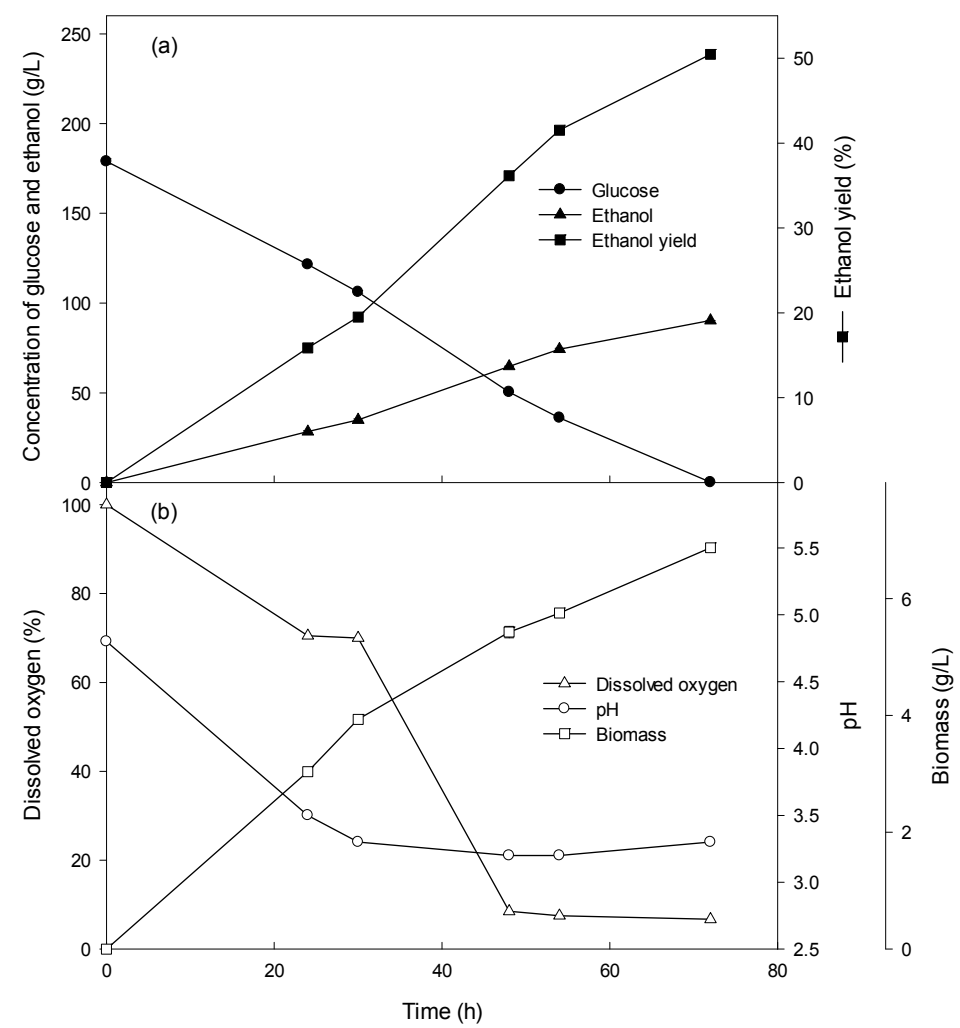

Figure 4. Time course of (a) glucose, ethanol concentration, and ethanol yield change, (b) dissolved oxygen, $\mathrm{pH}$, and biomass in the batch cultures of $S$. cerevisiae BCRC 21812. The initial glucose concentration was $18 \%(w / v)$.

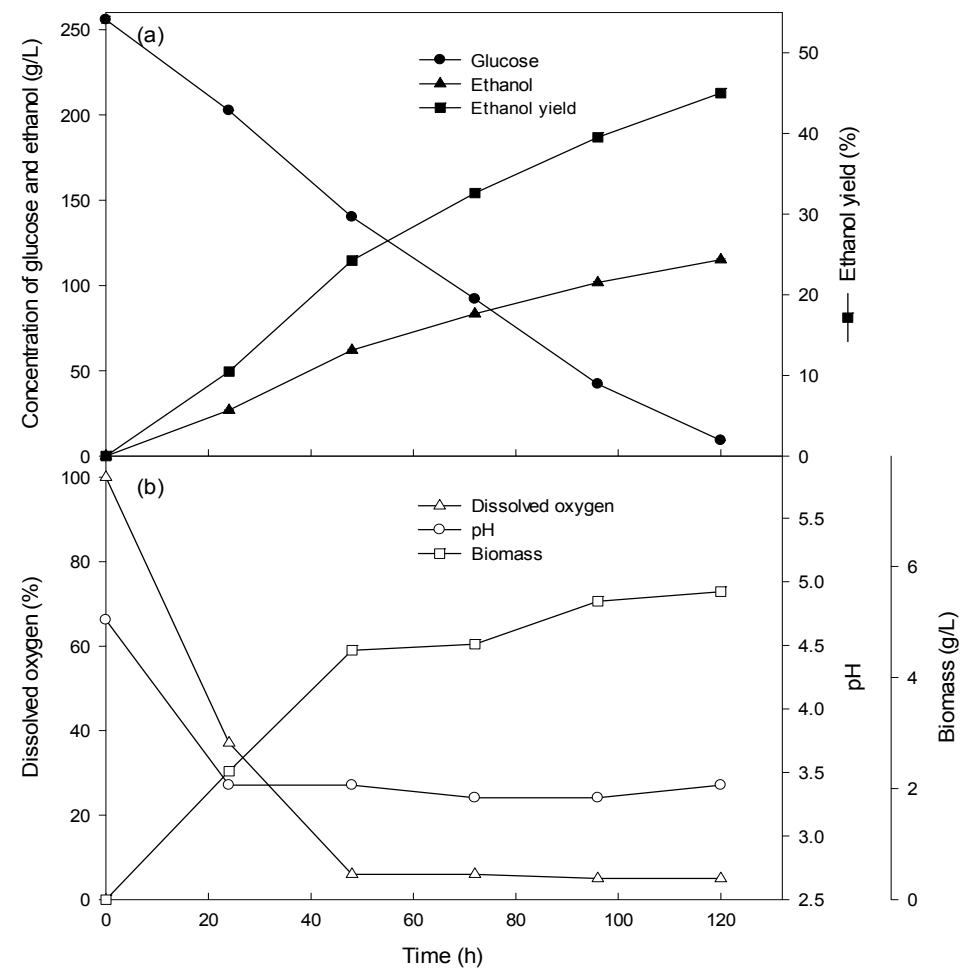

Figure 5. Time course of (a) glucose, ethanol concentration, and ethanol yield change, (b) dissolved oxygen, $\mathrm{pH}$, and biomass in the batch cultures of S. cerevisiae BCRC 21812. The initial glucose concentration was $26 \%(w / v)$. 


\subsection{Ethanol Production at High Glucose Concentration in the Fed-Batch Culture}

The time course of fed-batch fermentation with an initial 18\% $(w / v)$ glucose and addition of $4 \%(w / v)$ glucose after one and two days of incubation was demonstrated in Figure 6. Cell biomass increased gradually throughout the fermentation and reached the maximum of $8.3 \mathrm{~g} / \mathrm{L}$. When compared to the batch cultures with initial glucose concentrations of $26 \%(w / v)$, a significant increase in the volumetric cell mass production rate $(0.07 \mathrm{~g} / \mathrm{L} / \mathrm{h})$ and specific growth rate $(0.07 / \mathrm{h})$ were found in the fed-batch cultures after $120 \mathrm{~h}$ of fermentation. In general, there was no stationary phase of microbial growth observed for the fed-batch culture, at the glucose concentration feeding rates. It was found that glucose consumption rate in the fed-batch culture at the feeding mode was accelerated to $2.17 \mathrm{~g} / \mathrm{L} / \mathrm{h}$ and glucose was exhausted after $120 \mathrm{~h}$ of fermentation. Furthermore, ethanol concentrations and theoretical ethanol yield were greatly increased to $130.1 \mathrm{~g} / \mathrm{L}$ and $100 \%$, respectively (Table 2).

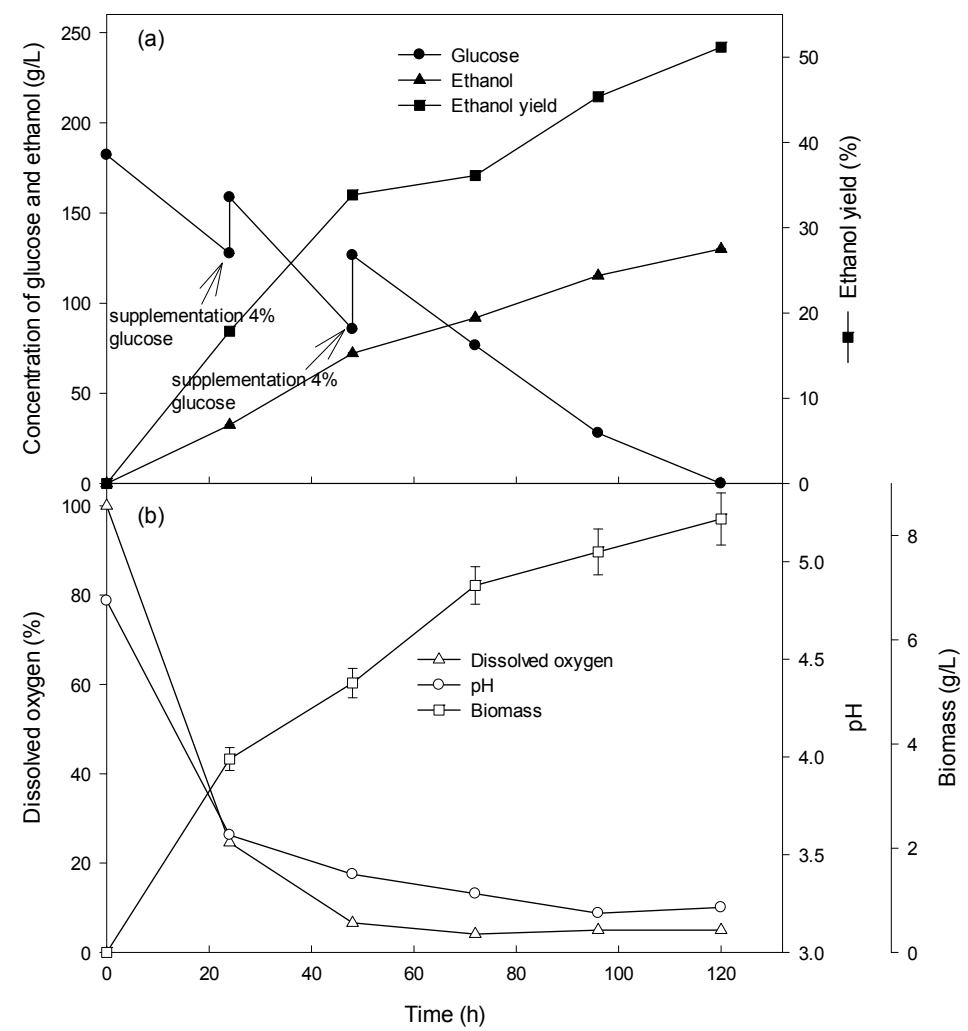

Figure 6. Time course of (a) glucose, ethanol concentration, and ethanol yield change, (b) dissolved oxygen, $\mathrm{pH}$, and biomass in the fed-batch cultures of S. cerevisiae BCRC 21812. The glucose concentration in the fermentation media was initially $18 \%(w / v)$ with an addition of $4 \%(w / v)$ glucose after one and two days of incubation, respectively.

\subsection{Comparison of Batch and Fed-Batch Culture for Ethanol Production}

Various concentrations of glucose that were used as the sole carbon source for ethanol production in a 5-L fermentor were shown in Table 2. Cell biomass of S. cerevisiae BCRC 21812 increased with the increasing concentration of glucose in the range of $1-20 \%(w / v)$. However, biomass concentrations decreased when the glucose concentrations were elevated to $26 \%(w / v)$. In addition, ethanol concentrations increased with the increasing concentration of glucose ranging $1-20 \%(w / v)$. The ethanol concentration was $102 \mathrm{~g} / \mathrm{L}$ when the initial glucose concentration in the batch culture was $20 \%(w / v)$. However, when the initial glucose concentration reached $26 \%(w / v)$, ethanol concentration $(115.1 \mathrm{~g} / \mathrm{L})$ did not significantly increase, indicating that the substrate had a considerable inhibitory effect. 
Table 2. Comparison of biomass, sugar, ethanol concentration and theoretical ethanol yield of $S$. cerevisiae BCRC 21812 by batch and fed-batch fermentation.

\begin{tabular}{cccccc}
\hline Fermentation Type & $\begin{array}{c}\text { Glucose } \\
\text { Concentration } \\
\mathbf{( g / L )}\end{array}$ & $\begin{array}{c}\text { Residual Glucose } \\
\text { Concentration } \\
\mathbf{( g / L )}\end{array}$ & $\begin{array}{c}\text { Maximal } \\
\text { Cell Biomass } \\
\mathbf{( g / L )}\end{array}$ & $\begin{array}{c}\text { Ethanol } \\
\text { Concentration } \\
\mathbf{( g / L )}\end{array}$ & $\begin{array}{c}\text { Theoretical } \\
\text { Ethanol } \\
\text { Yield (\%) }\end{array}$ \\
\hline & 10 & $\mathrm{ND}$ & $0.2 \pm 0.0$ & $5.1 \pm 0.0$ & $98.4 \pm 0.1$ \\
& 40 & $\mathrm{ND}$ & $1.7 \pm 0.1$ & $20.1 \pm 0.6$ & $98.2 \pm 0.2$ \\
Batch fermentation & 100 & $\mathrm{ND}$ & $5.1 \pm 0.2$ & $48.7 \pm 0.1$ & $99.6 \pm 0.4$ \\
& 150 & $\mathrm{ND}$ & $7.0 \pm 0.4$ & $77.5 \pm 0.2$ & $100.0 \pm 0.4$ \\
& 180 & $0.2 \pm 0.0$ & $6.9 \pm 0.4$ & $90.3 \pm 0.1$ & $98.2 \pm 0.3$ \\
& 200 & $0.2 \pm 0.0$ & $7.0 \pm 0.5$ & $101 \pm 0.1$ & $97.6 \pm 0.4$ \\
\hline Fed-batch fermentation & 260 & $9.1 \pm 0.1$ & $5.6 \pm 0.2$ & $115 \pm 0.5$ & $87.6 \pm 0.6$ \\
\hline
\end{tabular}

It was also noted that the residual concentrations of glucose were as high as $9.1 \mathrm{~g} / \mathrm{L}$ and the ethanol yield decreased to $0.45 \mathrm{~g}$ ethanol/g glucose when glucose concentrations in the cultural media were increased to $26 \%(w / v)$. However, a fed-batch mode of culture was performed to diminish the effect of substrate inhibition caused by high glucose concentrations. The initial glucose concentrations in the fed-batch culture were $18 \%(w / v)$ with an addition of $4 \%(w / v)$ glucose after one and two days of incubation, respectively. The results showed ethanol concentrations and conversion rate with the fed-batch cultures increased by $12 \%$ and $13 \%$, respectively, when compared to the batch cultures with $26 \%(w / v)$ glucose.

\section{Discussion}

High ethanol concentrations $(130 \mathrm{~g} / \mathrm{L})$ and high ethanol yield $(0.51 \mathrm{~g}$ ethanol/g glucose, $100 \%$ of the theoretical value) were achieved by the fed-batch cultures at the feeding concentration of $4 \%(w / v)$ glucose after one and two days of incubation and when final concentrations of glucose in the cultural media were $26 \%(w / v)$. It has been reported that decreases in the growth and viability of yeasts occur as sugar concentrations in the media increase from $12 \%$ to $18 \%(w / v)[9,11,12]$; however, when initial glucose concentrations were higher than $18 \%(w / v)$, they had a considerable inhibitory effect on yeast cell growth, ethanol concentration and ethanol yield. Our studies showed that the inhibitory effect on yeast cell growth as well as ethanol concentration and ethanol yield was diminished by the fed-batch mode of culture.

Theoretically, $1 \mathrm{~g}$ of glucose will produce $0.514 \mathrm{~g}$ of ethanol and $0.488 \mathrm{~g}$ of carbon dioxide. However, in practice, the microorganisms use some of the glucose for growth and the actual yield is less than $100 \%$. It is well known that fermentation efficiency is a key parameter for the industry. Based on the results shown in Table 1, efficient conversion of glucose to ethanol (around $100 \%$ of the theoretical value) was achieved for the batch cultures with $10-15 \%(w / v)$ glucose concentrations in the media. The results indicated that a very high efficiency was obtained at high sugar concentrations no greater than $20 \%(w / v)$ by the ethanol fermentation of S. cerevisiae BCRC 21812. However, a marked decrease in the ethanol yield to $44.7 \%$ ( $87.6 \%$ of the theoretical value) was observed when the initial glucose concentration was increased to $26 \%(w / v)$. The substrate inhibition effect was overcome by the fed-batch culture, which resulted in high ethanol concentration and ethanol yield. In addition, the ethanol yield obtained from our present study indicated efficient conversion of glucose to ethanol by S. cerevisiae BCRC 21812. The maximum ethanol yield in this study was significantly higher than those found in many literature reports. For example, Govindaswamy and Vane reported that $5 \%(w / v)$ of initial glucose concentration resulted in $0.49 \mathrm{~g}$ ethanol/g glucose of ethanol yield $(49 \%)$ by S. cerevisiae for the duration of $72 \mathrm{~h}$ of incubation period [26]. Kumar and colleagues found that an ethanol yield of $40 \%$ was obtained in the culture at initial sugar concentrations of $4 \%(w / v)$ [27].

The addition level and feeding times of glucose for the fed batch fermentation were determined from the consumption rate of the batch fermentation. It was observed that glucose was depleted by 
yeast after $24 \mathrm{~h}$ when the initial concentration of glucose was $4 \%(w / v)$ in the batch culture. From the start of the culture we proposed a strategy to feed glucose into the fermentation media for an interval of $24 \mathrm{~h}$ until the end of fermentation; however, extensive feeding of glucose (such as feeding more than $4 \%$ per day or total glucose concentration greater than $20 \%$ ) into the media resulted in decrease in biomass concentration and ethanol yields. As shown in the results by batch cultures, about $4 \%$ of glucose for every $24 \mathrm{~h}$ intervals was consumed by the yeast cell. The results of our study elucidated that the best protocol for the fed-batch cultures was feeding glucose at concentrations of $4 \%(w / v)$ after one and two days of incubation.

Comparatively, fed-batch cultures produced resulted in a better cell concentration than batch cultures did. Batch cultures in the fermentative media with glucose concentrations greater than $18 \%$ demonstrated a smoother type of growth. This growth might be attributed to the osmotic effect caused by the high glucose concentrations, resulting in the slower proliferation of yeast cells [28]. In contrast, the concentration of yeast biomass increased gradually and did not show any stationary phase for the fed-batch culture when initial glucose concentrations of the culture were adjusted to $18 \%(w / v)$ and glucose was added at feeding concentration of $4 \%(w / v)$ of its original concentration after one and two days of incubation. This was probably due to the feeding of $4 \%(w / v)$ glucose, which had provided a better growth environment for the yeast, allowing the yeast cells to divide more rapidly. The higher concentration of substrate was also found to affect the $\mathrm{pH}$, viscosity and the activity of the medium. Exposure to high glucose concentrations for a longer time might also cause catabolic repression. During the fermentation of ethanol, the cell growth rate was observed to be slightly affected by changing the cultural environment. Meanwhile, the increase of sugar concentration caused the decrease of cell viability. These observations were consistent with the results report by Bonin and Skwira [29].

\section{Conclusions}

In this study, we have demonstrated that maximal ethanol concentration and ethanol yield by a fed-batch culture can be achieved by the feeding mode proposed. Furthermore, we were able to increase the glucose consumption rate efficiently at very high glucose levels and decrease the time needed to obtain the maximal production of ethanol. Ethanol production with fed-batch fermentation offers advantages over production with batch fermentation. The conversion rate of ethanol from glucose was higher in fed-batch fermentation than it was in batch fermentation. Additionally, the inhibitory effects of the substrate on cell biomass and yields of ethanol were less pronounced for fed-batch fermentation than for batch fermentation. Moreover, it was noted that the maximum ethanol concentration and ethanol yield produced was as high as $130 \mathrm{~g} / \mathrm{L}$ and $51 \%$ in $120 \mathrm{~h}$ of fermentation. These achievements make the ethanol production process more industrially feasible and efficient. Further studies are focused on how to obtain high levels of ethanol production by applying the fed-batch mode of culture to a scaled-up fermentor.

Author Contributions: H.-D.J., Y.-H.C. and K.-S.C. designed and performed the experiments, derived the models and analyzed the data. C.-Y.C., T.-C.C. and C.-L.H. assisted with the experiments. H.-D.J. wrote the manuscript in consultation with Y.-H.C. and C.-L.H.

Funding: This work was supported by the Ministry of Science and Technology of the Republic of China (Taiwan) (NSC 97-2313-B-264-001-MY3).

Acknowledgments: The authors would like to thank the Ministry of Science and Technology of the Republic of China (Taiwan) for financially supporting this research under Contract No. NSC 97-2313-B-264-001-MY3.

Conflicts of Interest: The authors declare no conflicts of interest.

\section{References}

1. Bailey, B.K. Performance of ethanol as a transportation fuel. In Handbook on Bioethanol: Production and Utilization; Wayman, C.E., Ed.; Taylor \& Francis: Washington, DC, USA, 1996; pp. 37-60. 
2. Prasertwasu, S.; Khumsupan, D.; Komolwanich, T.; Chaisuwan, T.; Luengnaruemitchai, A.; Wongkasemjit, S. Efficient process for ethanol production from Thai Mission grass (Pennisetum polystachion). Bioresour. Technol. 2014, 163, 152-159. [CrossRef] [PubMed]

3. Lin, Y.; Zhang, W.; Li, C.; Sakakibara, K.; Tanaka, S.; Kong, H. Factors affecting ethanol fermentation using Saccharomyces cerevisiae BY4742. Biomass Bioenergy 2012, 47, 395-401. [CrossRef]

4. Morales, P.; Rojas, V.; Quirós, M.; Gonzalez, R. The impact of oxygen on the final alcohol content of wine fermented by a mixed starter culture. Appl. Microbiol. Cell Physiol. 2015, 99, 3993-4003. [CrossRef] [PubMed]

5. Ghorbani, F.; Younesi, H.; Ghasempouri, S.M.; Zinatizadeh, A.A.; Amini, M.; Daneshi, A. Application of response surface methodology for optimization of cadmium biosorption in an aqueous solution by Saccharomyces cerevisiae. Chem. Eng. J. 2008, 45, 267-275. [CrossRef]

6. Djekrif-Dakhmouche, S.; Gheribi-Aoulmi, Z.; Meraihi, Z.; Bennamoun, L. Application of a statistical design to the optimization of culture medium for alpha-amylase production by Aspergillus niger ATCC 16404 grown on orange waste powder. J. Food Eng. 2006, 73, 190-197. [CrossRef]

7. Gangadharan, D.; Sivaramakrishnan, S.; Nampoothiri, K.M.; Sukumaran, R.K.; Pandey, A. Response surface methodology for the optimization of alpha amylase production by Bacillus amyloliquefaciens. Bioresour. Technol. 2008, 99, 4597-4602. [CrossRef] [PubMed]

8. Ingledew, W.M. Alcohol Production by Saccharomyces Cerevisiae: A Yeast Primer, in the Alcohol Textbook, 3rd ed.; Nottingham University Press: Nottingham, UK, 1999.

9. Bafrnacová, P.; Smogrovicova, D.; Slavikova, I.; Atkova, J.; Domeny, Z. Improvement of very high gravity ethanol fermentation by media supplementation using Saccharomyces cerevisiae. Biotechnol. Lett. 1999, 21, 337-341. [CrossRef]

10. Casey, G.P.; Ingledew, W.M. Ethanol tolerance in yeast. Crit. Rev. Microbiol. 1986, 13, 219-280. [CrossRef] [PubMed]

11. Ivorra, C.; Pérez-Ortin, J.; Del Olmo, M. An inverse correlation between stress resistance and stuck fermentation in wine yeast: A molecular study. Biotechnol. Bioeng. 1999, 64, 698-708. [CrossRef]

12. Xu, P.; Thomas, A.; Gilson, C.D. Combined use of three methods for high concentration ethanol production by Saccharomyces cerevisiae. Biotechnol. Lett. 1996, 18, 1439-1440. [CrossRef]

13. Yamaoka, C.; Kurita, O.; Kubo, T. Improved ethanol tolerance of Saccharomyces cerevisiae in mixed cultures with Kluyveromyces lactis on high-sugar fermentation. Microbiol. Res. 2014, 169, 907-914. [CrossRef] [PubMed]

14. Liu, X.; Xu, W.; Zhang, C.; Yan, P.; Jia, S.; Xu, Z.; Zhang, C. Vitalized yeast with high ethanol productivity. RSC Adv. 2014, 4, 52299-52306. [CrossRef]

15. Thomas, K.; Hynes, S.H.; Ingledew, W.M. Effect of nitrogen limitation on synthesis of enzymes in Saccharomyces cerevisiae during fermentation of high concentration of carbohydrates. Biotechnol. Lett. 1996, 18, 1165-1168. [CrossRef]

16. Mauricio, J.C.; Salmon, J.M. Apparent loss of sugar transport activity in Saccharomyces cerevisiae may mainly account for maximum ethanol production during alcoholic fermentation. Biotechnol. Lett. 1992, 14, 577-582. [CrossRef]

17. Salmon, J.M.; Vincent, O.; Mauricio, J.M.; Bely, M.; Barre, P. Sugar transport inhibition and apparent loss of activity in Saccharomyces cerevisiae as a major limiting factor of enological fermentations. Am. J. Enol. Vitic. 1993, 44, 56-64.

18. Ciriacy, M.; Reifenberger, M. Hexose transport. In Yeast Sugar Metabolism; Zimmermann, F.K., Entian, K., Eds.; Technomic Publishing Company: Lancaster, PA, USA, 1997.

19. Bisson, L.F.; Neigeborn, L.; Carlson, M.; Fraenkel, D.G. The SNF3 gene is required for high-affinity glucose transport in Saccharomyces cerevisiae. J. Bacteriol. 1987, 169, 1656-1662. [CrossRef] [PubMed]

20. Caylak, B.; Vardar, S.F. Comparison of different production processes for bioethanol. Turk. J. Chem. 1996, $22,351-359$.

21. Alfenore, S.; Molina-Jouve, C.; Guillouet, S.E.; Uribelarrea, J.L.; Goma, G.; Benbadis, L. Improving ethanol production and viability of Saccharomyces cerevisiae by vitamin feeding strategy during fed batch process. Appl. Environ. Microbiol. 2002, 60, 67-72.

22. Stanbury, P.F.; Whitaker, A.; Hall, S.J. Principles of Fermentation Technology, 2nd ed.; Pergamon Press: Oxford, UK, 1995.

23. Alfenore, S.; Cameleyre, X.; Benbadis, L.; Bideaux, C.; Uribelarrea, J.L.; Goma, G.; Molina-Jourve, C.; Guillouet, S.E. Aeration strategy: A need for very high ethanol performance in Saccharomyces cerevisiae fed-batch process. Appl. Microbiol. Biotechnol. 2004, 63, 537-542. [CrossRef] [PubMed] 
24. Chang, Y.H.; Chang, K.S.; Huang, C.W.; Hsu, C.L.; Jang, H.D. Comparison of batch and fed-batch fermentations using corncob hydrolysate for bioethanol production. Fuel 2012, 97, 166-173. [CrossRef]

25. Miller, G.L. Use of dinitrosalicylic acid reagent for determination of reducing sugar. Anal. Chem. 1959, 31, 426-428. [CrossRef]

26. Govindaswamy, S.; Vane, L.M. Multi-stage continuous culture fermentation of glucose-xylose mixtures to fuel ethanol using genetically engineered Saccharomyces cerevisiae 424S. Bioresour. Technol. 2010, 101, 1277-1284. [CrossRef] [PubMed]

27. Kumar, R.S.; Shankar, T.; Anandapandian, K.T.K. Characterization of alcohol resistant yeast Saccharomyces cerevisiae isolated from Toddy. Int. Res. J. Microbiol. 2011, 2, 339-405.

28. Cheng, N.G.; Hasan, M.; Kumoro, A.C.; Ling, C.F.; Tham, M. Production of ethanol by fed-batch fermentation. Pertanika J. Sci. Technol. 2009, 17, 399-408.

29. Bonin, S.; Skwira, J. Effect of continuous fermentation of high-sugar fruit must on the viability and morphology of immobilized yeast on white foam glass. Food Technol. Biotechnol. 2008, 46, 164-170.

(C) 2018 by the authors. Licensee MDPI, Basel, Switzerland. This article is an open access article distributed under the terms and conditions of the Creative Commons Attribution (CC BY) license (http:// creativecommons.org/licenses/by/4.0/). 